\title{
Inventory: Catalyst for Collection Development
}

\author{
Daniel L. Shouse \\ Linda Teel
}

\section{The Authors}

\author{
Daniel L. Shouse, East Carolina University, Greenville, North Carolina, USA \\ Linda Teel, East Carolina University, Greenville, North Carolina, USA
}

\begin{abstract}
$\underline{\text { Abstract }}$
Purpose - The intent of this article is to show the direct outcomes of an inventory project, which served as the catalyst for collection development improvements.
\end{abstract}

Design / methodology / approach - An inventory project was undertaken with a major emphasis on the outcomes derived from the inventory.

Findings - Several types of problems were discovered, such as missing items, incorrect information (call numbers, collection codes, item types, etc...), damaged materials, and weaknesses in the collection, which resulted in major improvements and changes in the development of the collection.

Originality / value - The results of the inventory project improved the accessibility of the collection to patrons by correcting many inconsistencies involving the shelving of materials, online records, call numbers, collection codes, item types, and bar codes. The location of missing items as well as identified areas of strengths and weaknesses assisted with collection development activities. The results of the project also provided an opportunity to hire a consulting firm to further assess the collection, which led to additional funds for supporting the collection. The single major benefit of the inventory process was it provided the catalyst for instigating major changes in the curriculum collection development of the Teaching Resources Center.

Article Type: Case Study

Keywords: inventory, collection management, collection development, curriculum materials centers, weeding, academic libraries

\section{Introduction}

The Teaching Resources Center (TRC) provides a heavily used collection of print and non-print resources that support the university's curriculum specializing in the initial training and professional growth of early childhood educators and Kindergarten through $12^{\text {th }}$ grade $(\mathrm{K}-12)$ public school teachers. The collection includes North Carolina state adopted textbooks for K-12 instruction, children's and young adult fiction and nonfiction literature, easy picture books, biographies, reference materials and audiovisual resources such as videos, DVDs, CD-ROMs, and audio tapes.

The TRC originated in 1988 as a small department serving as a resource for preservice teachers and area educators. As the department and the collection expanded, the TRC moved four times within the library to accommodate the growth. In May of 2002, the TRC moved into its current location where it houses a collection of more than 56,000 items. With the considerable growth and changes in the collection during the recent years, a determination was made to conduct a thorough inventory of the collection to properly assess the strengths and weaknesses. Because 
the collection consisted of various classifications and collection codes, and no record existed of an inventory ever being conducted, this project was a vast undertaking. Regardless of the magnitude of the project, it was decided that it must be conducted because collection assessment was an essential step in future collection development. With this consideration, the results of the inventory project provided the catalyst to challenge and redefine the emphasis in developing the future collection of the Teaching Resources Center.

\section{Literature Review}

While the literature provides substantial numbers of articles on the topics of inventory, collection management and collection analysis, limited literature exists specific to Curriculum Materials Center (CMC) collections. Curriculum Materials Centers offer educational resources that provide curriculum and instructional support for P-12 students. Educators incorporate these materials in the development of curricula and lesson plans, research and instruction. In terms of inventory and collection development, school media centers have similar goals to those of Curriculum Materials Centers. Braxton (2005) provides a listing of benefits and outcomes resulting from a school media center inventory, which once examined reveals comparisons useful in a CMC collection. Ernick (2005) describes a step-by-step account of an inventory project in a small college collection including problems encountered and resulting benefits. This article provides valuable feedback in regard to database corrections at simple and complex levels. Slote (1997) includes helpful observations about the important and often neglected weeding of collections emphasizing the value of a current collection for users. The Association of College and Research Libraries (1993) describes the creation and writing of a Curriculum Materials Center collection development policy with actual sample policies, which serve as guides in the revision of policies. Jackson (2005) culminates a wealth of experience and knowledge specific to the North Carolina Standard Course of Study including collection analysis to focus on developing a CMC collection based on the North Carolina school curriculum. The newly approved and developed CMC guidelines from the American Library Association (2005) in conjunction with Carr's (2001) management guide offer the perfect guidance for focusing attention on collection development based on the outcomes of the inventory. The content of this article used the literature of monographs and journal articles to derive comparisons of inventory benefits. The benefits of the inventory provided the catalyst to determine strategies for improvements based on collection analysis.

\section{Purpose of the project}

The initial reasons for undertaking a project of this magnitude were simple: to assess the age, accuracy, and condition of the collection, as well as to address problems within the collection by which their resolution would provide patrons with more accurate accessibility to the materials. Once the inventory was completed, the department used outcomes and results to develop strategies and criteria to improve the collection. Prior to conducting the inventory, difficulties arose frequently when assisting users in locating materials on the shelves. The inventory project located missing and misshelved materials, which was crucial to improving access. Additionally, the inventory:

...ensured that Horizon records existed in our online catalog for all materials

...placed materials in proper call number order on the shelves

...identified outdated and worn materials that needed to be replaced or discarded

...identified collection weaknesses based on the North Carolina Standard Course of Study. 


\section{The Process}

Several types of materials existed in the TRC collection. For each type of material inventoried a report was generated from Horizon, the library's online system, that provided such information as collection code, item type, call number, copy holdings, title, bar code, item status, quantity of circulation along with the last check out date. Not only was this information valuable during the inventory process, but it was useful in determining the direction for future collection development. For instance, reviewing the number of checkouts along with the last checkout date provided two useful variables in determining deselection of items in the collection. Data that showed an item had little or no circulation, or had not been circulated in several years, assisted in determining whether the item remained in the collection or was withdrawn. Numerous check outs of an item indicated the need to retain the item.

The bar code of each item included in these reports, served as a unique identifier for all items. The bar code proved valuable when searching for items that had known problems. For example, the bar code search option was used when an item was found on the shelf, but was not listed in the report. By conducting a bar code search in the cataloging module of Horizon, the item record was retrieved. Once retrieved, examination of the item in question provided information to determine the correct item type, collection code, or call number. Any inaccurate information was easily corrected.

\section{Outcomes and Results}

During the course of conducting the inventory project several types of problems surfaced. Just as recorded in Linda Ernick's article, the inventory allowed for database cleanup on both simple and complex levels (Ernick, 2005). Beginning on a simple level, the status of many items was corrected. For example, two types of "missing" items were discovered. Some materials with "item missing" status in the report actually appeared on the shelves. To correct this problem these materials were simply checked into the system eliminating the "item missing" status. Conversely, some materials listed in the report as checked-in were not on the shelves. This posed an entirely different problem that required an alternative solution. Actually, a third type of "item missing" status problem evolved. Some materials found on the shelves lacked existing records in the online cataloging system. This unexpected problem definitely required attention and correction. Once identified, the items were either entered into the system or discarded based on the weeding criteria. The origin of this problem was unknown, but one theory proposed that during migration from the previous online system some of the item records did not migrate properly.

Additionally, the discovery of frequent problems related to incorrect call numbers appeared. Instant corrections made to these items permitted easier accessibility for patrons. Two of the most recurring problems involved items with incorrect item types and collection codes. Fortunately, these problems were easily and quickly corrected. Infrequently, some materials inventoried belonged in the general stacks or in other collections within the library. In one case, an item belonged to another library.

A more complex level of problems surfaced with duplicate records, and "orphan bar codes" (Ernick, 2005). These orphan bar codes arose when items had been assigned a bar code, but the bar code was never entered into the system replacing the temporary or orphan bar code (Ernick, 2005). The lists created from Horizon to conduct the inventory project revealed many temporary bar codes on the lists. Records with temporary bar codes should have been removed or merged when the main record was created for the item. Apparently, many of these temporary records were not removed or changed creating additional problems. Corrections to these 
problems had to be addressed by the cataloging department. Upon completion of the inventory project, the cataloging department received the list of items with duplicate records. A cataloger checked the list with the system and returned the list of the items that had been corrected. In collaboration with the cataloging department, the duplicate record problems were resolved.

Another outcome involving damaged materials was identified during the inventory process. One of the main accomplishments of the inventory project located damaged and outdated items in the collection in order to withdraw and replace them with new copies or more appropriate and current materials. Once identified as damaged, the preservation and conservation department reviewed each item to provide feedback to the TRC on cost of repair, binding or replacement. Based on these factors, a solution was determined.

The most significant outcome of the process revealed the identification of collection weaknesses. Weaknesses in several areas of the collection were noted based upon the age of items, condition of items, or deficiency of items in a particular subject area. Addressing such weaknesses would be a crucial step for the department to successfully convey the effectiveness of the collection in meeting the needs of the users.

Overall, the process of inventory provided the opportunity for TRC professionals to analyze the collection based on the physical and statistical review of individual materials as well as the collection's entirety. Through the analysis of the collection, three immediate observations surfaced. First, the collection had three major glaring weaknesses in the areas of award winning titles, reference titles, and nonfiction materials. Using printed reports compiled for inventory purposes, librarians analyzed and compared circulations and copyright/publication dates of materials, which revealed the need for massive updating of reference and nonfiction titles. Further examination of the reports noted a high absence rate of award winning titles. This observation was also validated by the high number of user requests to purchase such titles. Second, the development of the collection needed dedicated professional guidance. Once the inventory was completed and the data was analyzed, it became evident that one of the primary reasons for the state of the collection directly related to the lack of a dedicated curriculum specialist to develop the collection. Through the years, the rapid collection growth to more than 50,000 titles validated the need for a professional with school curriculum knowledge and experience to develop such a specialized collection. Third, the collection development policy for the collection needed major revisions. Evidence from the inventory supported the need for major revisions in the collection development policy including the amount of worn and outdated materials on the shelves. Apparently, deselection needed to be readdressed and fully implemented in the existing policy. The complete analysis of the inventory revealed that a plan of action was needed to improve the development and reliability of the collection. Even though a formal collection analysis without the inventory could have been accomplished with similar objectives, the inventory corrected many problems improving the accuracy of the collection. Evaluating the collection strengths and weaknesses was improved and easier based on the accuracy provided through the inventory process. In comparison to Barbara Braxton's article, another important positive outcome of the inventory centralized on the fact that it produced evidence and solid support to validate a plan of action. The results of the inventory clarified the challenges and issues in the collection that needed to be address by providing documentation to gain support from an informed and knowledgeable basis (Braxton, 2005).

\section{Plan of Action}

A plan of action was needed to address the issues necessary to improve the collection based on the inventory outcomes and results. The first step in the plan of action included the revision of the collection development policy. Using A Guide to the Management of Curriculum Materials Centers for the $21^{\text {st }}$ Century, the collection development policy was revised to reflect the four recommended criteria that should be used in making material selection and deselection decisions 
for a curriculum materials center: 1) Duplication/Deficiency, 2) Condition/Format, 3) Authority/Content, and 4) Relevance/Currency (Carr, 2001). In conjunction with the four recommended criteria, the recent publication of the Guidelines for Curriculum Materials Centers from the Association of College and Research Libraries provided valuable guidance in developing the general characteristics, collection categories and development areas that needed to be addressed by the policy (American Library Association, 2005). The Curriculum Materials Center Collection Development Policy, developed by two joint subcommittees of the Problems of Access and Control of Education Materials Committee served as a resource in the careful examination and updating of the existing policy. Sample policies located in the appendices supplied examples for addressing each section to be included in the policy (Association of College and Research Libraries Education and Behavioral Sciences Section, 1993). Upon the revision of the policy and the approval of the final document, the department further realized that a dedicated professional was essential to provide experienced knowledge of the North Carolina Standard Course of Study in order to develop the collection properly. This professional needed to be primarily responsible for the development of the curriculum collection based on the collection development policy as it related to the North Carolina Standard Course of Study. In the past, the responsibility for the curriculum collection development had been divided among three staff members who were limited by time and budget in their efforts. An additional factor that further inhibited the development of collection evolved from the fact that the TRC position responsible for the development of the nonfiction collection had been vacant for more than a year.

Realizing that one of the solutions for improving the collection included requesting an additional faculty position allocation to the department, a proposal was presented to the library administration and faculty assembly for consideration and discussion. Showing the link to the need for a professional curriculum specialist position to the outcomes of the inventory based on the statistical data validated and supported the request. The data also provided the evidence proving that the worn and obsolete materials were not circulated by patrons because the materials no longer supported the curriculum or met the needs of the patrons. Upon the presentation of the job proposal based on the data, the allocation of a TRC Curriculum Specialist position was supported and approved for the department. With this allocation, the second step of the plan of action was accomplished. The job search was initiated and the position was filled. Dedicated collection development was established and implemented.

The third action of the plan involved the improvement of the collection, which required additional funding and budget allocations for the department. The inventory revealed three apparent weaknesses in the collection: 1) award titles, 2) reference titles, and 3) nonfiction titles. Statistically, the collection lacked over $75 \%$ of the notable award winning titles. Requested emergency action addressed this major concern. With the cooperation of the acquisitions department and administration, additional funding allocated to implement an approval plan provided $90 \%$ of the recognized award winning titles in children's literature. With the plan initially adding more than 475 titles in the first year, the continuation of the plan totally eliminated the deficiency of award winning titles. The second and third weaknesses discovered as a result of the inventory project were a major challenge financially. Documentation and concrete evidence addressed the improvements needed in this area in order to secure significant funding to correct them. To document and prepare a detailed analysis of the nonfiction collection weaknesses, an extraordinary amount of dedicated time would be needed to analyze the collection. Considering the time constraints and heavy work loads of the staff, a request to contract a consulting firm to accomplish this task was considered and approved by the administration and the faculty assembly.

In the summer of 2005 the consulting firm, Library Services Unlimited, conducted a comprehensive assessment of the print collection and the facility arrangements of the TRC. A five day review and visit to the center produced a written document of recommendations based on reports, statistics and standards. One of the statements made in the consultant's final report was, "no information is better than misinformation" (Jackson, 2005), which was exactly what the majority of the older books in the collection were providing. An example of misinformation 
included books on computer science that still referred to punch cards. Another example focused on books of countries that no longer existed. Having books about the Soviet Union (USSR) provided resources for historical research, but not current information for preservice teachers to integrate into classroom instruction. Stanley J. Slote's Weeding Library Collections notes that "a library that is serving its clientele properly needs to have a collection that is up-to-date and changing" (Slote, 1997).

Statistically speaking, the consultant reported that "approximately $86.4 \%$ of the nonfiction collection is more than 10 years old $(4.0 \%$ is less than 5 years old) reflecting a need to aggressively up-date the collection through deselection/weeding and new acquisitions. A general rule-of-thumb is $80 \%$ of the nonfiction collection would be no older than ten years. Special attention needed to be given to areas with rapidly changing subject matter, e.g., the social sciences (300's), technology (000's and 600's), and geography/travel (900's)" (Jackson, 2005).

In conjunction with nonfiction materials, the consultant's report recommended that the TRC reference collection be strengthened and made up-to-date to reflect the K-12 curricula. The consultant's analysis indicated that $41.3 \%$ of the reference collection was less than ten years old. A general rule-of-thumb suggests that $70 \%$ of the reference collection should be less than ten years old (Jackson, 2005). To assist with the development and updating of the reference collection, a local reviewer contributed valuable reference materials to the collection totaling in excess of six thousand dollars annually. The continuation of donated reference materials assist tremendously with the identified deficiencies in this area of the collection.

The consultant's report was extremely useful. Even though weaknesses were identified through the inventory project, the consultant's report was instrumental in documenting written evidence of the needs. Although the consultant's report highlighted that the nonfiction collection was extremely old and out-of-date, the report proved to be very beneficial. The staff knew that the collection needed to be aggressively weeded and now written proof existed supporting the action. The consultant's report helped the department seek financial assistance to correct the weaknesses. The consultant documented, "The current budget is inadequate to update the Teaching Resources Center collection. An investigation of several new schools' opening day or basic collection showed an expenditure of approximately $\$ 150,000$ per school" (Jackson, 2005). These comments were powerful because the current departmental budget could not begin to address nor correct the aging collection. The consultant's report provided concrete evidence justifying the request for additional funding to update the collection. The consultant's recommendation also stated: "Seek additional funding that would provide a minimum of one book title per student in the College of Education per year." The consultant noted that a minimum of $\$ 30,000$ per year in additional funds for books for the next five years would be needed to realize the goal of having a desirable basic K-12 collection" (Jackson, 2005). Having this information from an outside source gave credence to our request for additional funding from administration.

The report presented to the library administration and faculty assembly supported the request for additional budget allocations to address the glaring weaknesses. Initially, an additional $\$ 30 \mathrm{~K}$ was granted to begin the updating and development of the nonfiction collection with an additional $\$ 20 \mathrm{~K}$ allocated to focus on materials to support the birth to kindergarten curriculum. A massive weeding project based on the newly revised collection development policy initiated the withdrawal of the outdated materials. The initial implementation of the plan of action began successfully.

\section{Conclusion}

The decision to conduct a complete inventory of the collection was easily and quickly determined; however, the process took several months to complete. The initial objective of the inventory was to ensure that the automated cataloging system accurately reflected the collection. Prior to the inventory, patrons expressed great difficulties locating materials based on the inconsistencies with the catalog and the actual shelved materials. The inventory process addressed and eliminated a majority of these concerns. In conjunction with the completed inventory, search limits 
incorporated in the online catalog allowed patrons to search specifically by curriculum collection, as well as by collection types such as easy books, fiction, nonfiction, etc. With the accuracy of the collection greatly improved and the search limits in place, attention focused on properly developing the collection to meet the needs of the users. The inventory identified an overwhelming weakness of the nonfiction collection of the center. Circulation statistics revealed that the majority of the nonfiction books were not being checked out, and the departmental staff realized that many times the center did not have the current materials patrons needed. As disturbing as the facts appeared, a plan of action was implemented to improve the collection in order to meet the immediate needs of the users. To improve the collection, the support of the entire library was gained through the presentation of the facts at a meeting of the administration and faculty. The results of the inventory project, along with the consultant's report and recommendations for improvements were the key factors to addressing the weaknesses of the collection and providing a sense of urgency to improve the collection.

The TRC utilized the results of the inventory to improve the accessibility of the collection to patrons by correcting many inconsistencies involving the shelving of materials, online records, call numbers, collection codes, item types, and bar codes. The location of missing items as well as identified areas of strengths and weaknesses assisted with collection management and development now and in the future. The inventory accented the need for a detailed collection development policy to be applied by a dedicated faculty member responsible for collection development. Finally, it allowed the opportunity for an entire library to support the improvements through additional funding and allocations. With the initial implementation of the plan of action, the Teaching Resources Center experienced a 38\% increase in circulation. In retrospect, the single major benefit of the inventory process was it provided the catalyst for instigating major changes in the curriculum collection development of the Teaching Resources Center.

\section{$\underline{\text { References }}$}

American Library Association (2005), Guidelines for Curriculum Materials Centers [online]. [Accessed 10th February 2005]. Available from World Wide Web: < http://www.ala.org/ala/acrl/acrlstandards/guidelinescurriculum.htm>

Association of College and Research Libraries Education and Behavioral Sciences Section (1993), Curriculum Materials Center Collection Development Policy, Chicago: American Library Association. pp. 22-38.

Braxton, Barbara (2005), "Inventory: 26 Reasons for Doing One", Teacher Librarian, 32(4), p. 53.

Carr, Jo Ann, ed. (2001). A Guide to the Management of Curriculum Materials Centers for the $21^{\text {st }}$ Century: the Promise and the Challenge, Chicago: Association of College and Research Libraries, pp. 59-62.

Ernick, Linda (2005), "Floating Bibs and Orphan Bar Codes", Library Resources \& Technical Services, 49(3), p. 214.

Jackson, Gwen G. (2005), Collection and Facility Assessment of the Teaching Resources Center, Joyner Library, East Carolina University, Swansboro, NC: Library Services Unlimited, pp.1-4.

Slote, Stanley J. (1997), Weeding Library Collections: Library Weeding Methods, $4^{\text {th }}$ ed.

Englewood, Colorado: Libraries Unlimited, Inc., p.6. 